\title{
Alcances e limites de um CCT Program: quão justificadas são as críticas ao Bolsa Família?
}

\author{
Scope and limits of a CCT Program: how justified is criticism \\ against the Bolsa Familia?
}

\author{
Alessandro Pinzani \\ alessandro@cfh.ufsc.br \\ (Universidade Federal de Santa Catarina, Florianópolis, Brasil)
}

\begin{abstract}
Resumo: As reflexões que Rúrion Melo apresenta em sua resenha ao livro Vozes do Bolsa Família, ${ }^{1}$ do qual ele se demonstrou leitor atento e benévolo, me instigaram não tanto a uma réplica direta, pois não há no seu texto críticas à nossa análise e à nossa tese, quanto a propor algumas considerações que, em parte, se movimentam na esteira de alguns argumentos do próprio Melo e, em parte, representam uma tentativa de responder a algumas das críticas avançadas ao Programa Bolsa Família e aos CCT Programs ${ }^{2}$ mencionadas na resenha, embora não endossadas pelo seu autor.
\end{abstract}

Palavras-chave: Bolsa Família; programas CCT; justiça social; políticas sociais.
Abstract: The reflections that Rúrion Melo has made in his review of the book Vozes do Bolsa Familia, which he read with benevolent attention, prompted me not so much to issue a direct reply, rather to propose some considerations that, in part, move in the wake of some of Melo's own arguments and, in part, represent an attempt to answer some of the criticisms to the Bolsa Família program that were mentioned in the review, although not endorsed by the author. In particular, I shall contextualize the Bolsa Família program and try to answer to some basic objection to CCT programs both as cash transfer programs and as conditional programs. Finally, I shall try to offer some remarks on the future of the program according to the possible political scenarios opened by the 2014 general election in Brazil.

Keywords: Bolsa Família; CCT Programs; social justice; social policies.

DOI: http://dx.doi.org/10.11606/issn.2318-9800.v19i2p149-163

1. MELO, R. Resenha de Vozes do Bolsa Família: Autonomia, dinheiro e cidadania, de Walquiria Leão Rego e Alessandro Pinzani (São Paulo: Editora Unesp, 2013). Cadernos de Filosofia Alemãa, vol. 19, n 1, 2014, pp.213-221.

2. Conditional Cash Transfer Programs. 


\section{O Programa Bolsa Família em contexto}

Em primeiro lugar, gostaria de colocar o Programa Bolsa Família (doravante PBF) no seu contexto específico. O PBF é um dos quase sessenta programas de combate à pobreza implementados pelo Ministério do Desenvolvimento Social. Isso significa que, se quisermos analisar seu impacto do ponto de vista da erradicação da miséria e da criação de uma sociedade menos desigual, deveríamos levar em conta a maneira em que ele interage com os demais programas. Por isso seria incorreto acusar o governo federal de estar lutando contra pobreza e desigualdade somente através do PBF, como fazem alguns críticos, inclusive de esquerda. Durante nossas entrevistas, por exemplo, constatamos que a maioria das famílias estava participando de outros programas além do PBF: o Luz para Todos, o Seguro Safra, programas para agricultura cooperativa, etc. Com certeza o $\mathrm{PBF}$ não pode eliminar a pobreza sozinho e ninguém pensa que o possa, nem sequer em Brasília (aliás, sobretudo em Brasília). Se o PBF está na boca de todos e no centro do debate é, por um lado, pela extensão que o programa alcançou, atingindo mais de um quarto dos brasileiros ( 55 milhões de pessoas) e, por outro, pelo fato de resultar numa transferência monetária direta, em vez de na provisão de serviços como a maioria dos outros programas (alguns deles também distribuem dinheiro, mas tal distribuição é vinculada à compra de bens específicos, como nos programas de apoios a pequenos agricultores ou às cooperativas). É este último aspecto aquele que suscita as maiores polêmicas e voltarei a ele na segunda seção deste escrito.

Em segundo lugar, o PBF é um CCT program, ou seja, um programa de transferência condicional de renda. Existem há vários anos muitos estudos sobre este tipo de programa e quase todos avaliam positivamente seu impacto, particularmente por sua eficácia em quebrar o conhecido "círculo vicioso" da pobreza: o abandono escolar, provocado pela necessidade de as crianças trabalharem para prover uma fonte adicional de renda para a família, acaba perpetuando a situação de miséria. Claramente, isso não significa que toda e qualquer criança que permanece na escola terá automaticamente uma vida melhor do que a de seus pais, pois isso depende de muitos fatores (principalmente da qualidade do ensino), mas pode-se dizer que um primeiro passo, necessário, embora não suficiente, foi feito. Sobre as críticas às condicionalidades e ao próprio caráter condicional voltarei na terceira seção. 
Finalmente, a avaliação política do PBF (sua presumida timidez, por exemplo) precisaria ser inserida em uma avaliação mais geral da política brasileira dos últimos doze anos e deveria levar em conta as circunstâncias políticas nas quais o programa foi lançado, implementado e sucessivamente ampliado. ${ }^{3} \mathrm{Na}$ impossibilidade de realizar uma análise deste tipo neste contexto, limitar-me-ei a algumas poucas considerações genéricas na quarta e última seção.

Não abordarei neste contexto a questão do caráter desenvolvimentista das políticas sociais dos governos petistas, pois para isso precisaria de uma discussão prévia sobre o caráter do próprio desenvolvimentismo. ${ }^{4}$

\section{Não tem peixe no sertão}

Um dos argumentos mais utilizados pelos adversários "conservadores" do PBF é o de que este não ajudaria os pobres a sair definitivamente da pobreza, limitando-se a sustentá-los e a torná-los dependentes do Estado. ${ }^{5}$ Seria um programa meramente assistencialista que criaria uma atitude de acomodação em seus beneficiários. ${ }^{6}$ Durante os muitos debates sobre nosso livro tivemos que ouvir inúmeras vezes o provérbio chinês "ensina-lhes a pescar, em vez de dar-lhe o peixe". Sempre respondia que no sertão não tem peixe. Fora de metáfora, as críticas que apontam para a insuficiência do PBF para erradicar de vez a pobreza parecem não levar em conta pelo menos dois aspectos. $\mathrm{O}$

3. Veja-se sobre isso, além dos textos indicados por Melo em sua resenha, o livro: CAMPELLO, T.; NERI, M. (orgs.). Programa Bolsa Família. Uma década de inclusão e cidadania. Brasília: IPEA, 2013.

4. Sobre o tema ver: MOLLO, M.; FONSECA, P. Desenvolvimentismo e novo-desenvolvimentismo: raízes teóricas e precisões conceituais. Brazilian Journal of Political Economy, vol. 33, n 2, 2013, 222-239; FONSECA, P.; CUNHA, A.; BICHARA, J. O Brasil na Era Lula: Retorno ao desenvolvimentismo? Nova Economia, vol. 23, n 2, 2013, pp. 403-428.

5. Na realidade, segundo dados oficiais, $75,4 \%$ dos participantes do PBF trabalham (http:/www.brasil.gov.br/cidadania-e-justica/2014/05/bolsa-familia-75-4-dos-beneficiarios-estao-trabalhando).

6. Já em 2006 Celia Kerstenetzky colocava claramente os diferentes conceitos de justiça social que se enfrentam no debate sobre políticas sociais no Brasil em KERSTENETZKY, C. Políticas sociais: focalização ou universalização? Revista de Economia Política, vol. 26. № 4 (104), 2006, 564-574. 
primeiro é o fato, já mencionado, de que o PBF é somente um entre muitos programas sociais do governo federal (sem contar os programas de alguns governos estaduais e municipais) e que, portanto, ninguém o considera e o pode considerar como o único instrumento para eliminar milagrosamente o problema da pobreza. O segundo aspecto diz respeito à situação de boa parte dos participantes do programa, uma vez que a metade deles vive em áreas rurais bastante isoladas e sem infraestrutura capaz de atrair investimentos privados e, destarte, permitir a criação de empregos. ${ }^{7}$ Nenhum empresário abrirá uma fábrica ou outro tipo de empresa no meio do sertão ou no vale do Jequitinhonha, a centenas de quilômetros do próximo porto ou aeroporto, em regiões ligadas ao resto do país somente através de estradas em condições péssimas ou precárias, e cuja população não dispõe da mínima preparação para trabalhos qualificados. Essa situação não pode mudar no curto prazo sem investimentos maciços por parte do Estado (em nível federal e estadual) e sem uma política de tipo keynesiano, como aquela adotada nos EUA na era do New Deal. Contudo, não me parece que no momento existam as condições políticas para esse tipo de intervenção (sobre esse ponto voltarei na quarta seção).

Ainda assim, o programa está tendo efeitos positivos do ponto de vista do desenvolvimento econômico dessas regiões, embora se trate de melhorias relativamente pequenas. As condições de vida material das pessoas melhoraram e surgiu o que alguns economistas chamam de "economia de pobre para pobre": ${ }^{8}$ os participantes do programa utilizam às vezes o dinheiro para iniciar microempresas (criação de animais de pequeno porte, artesanato, etc.), trazendo um pouco de movimento em situações caracterizadas anteriormente pela ausência de qualquer transação econômica relevante. Contudo, não é por meio desses tipos de fenômenos econômicos ainda bastante rudimentares que será possível eliminar definitivamente a pobreza dessas regiões - pelo menos a curto e médio prazo.

7. "Segundo o IBGE, 46,7\% das pessoas na linha de extrema pobreza residem em área rural, apesar de apenas $15,6 \%$ da população brasileira morar no campo. O restante das pessoas em condição de miséria, 53,3\% mora em áreas urbanas, onde reside a maioria da população - 84,4\%" (citado de: http:// g1.globo.com/politica/noticia/2011/05/brasil-tem-1627-milhoes-de-pessoas-em-situacao-de-extrema-pobreza.html).

8. http://www.bancodocidadao.com.br/noticias/?vCod $=212$ 
A situação é diferente nas áreas urbanas, onde, porém, outros problemas dificultam a saída da pobreza dos participantes, começando pelos custos de vida mais elevados, que acabam sempre expulsando-os para as margens da sociedade. Nesse caso, o problema não é a falta de emprego, mas o nível miserável dos salários - um aspecto, a meu ver, que ainda não está bastante presente no debate público e até no debate acadêmico. Ninguém pode acreditar seriamente que o salário mínimo seja suficiente para garantir uma vida digna a quem o recebe, particularmente no contexto de uma grande cidade. $\mathrm{O}$ que dizer, então, quando ele é a única fonte de renda em uma família ou quando os empresários se recusam até a pagá-lo, como acontece em muitos empregos informais?

Em outras palavras, o que se esquece no debate sobre o presumido caráter assistencialista do PBF e sua insuficiência em eliminar as causas da pobreza é que a eliminação de tais causas deveria passar por uma série de políticas públicas (grandes obras públicas em todo o país, investimentos enormes em infraestrutura e formação profissional, aumento dos salários por lei, etc.) de tamanho alcance que seria legítimo falar em uma verdadeira revolução política, cuja possibilidade no momento me parece extremamente remota (como tentarei argumentar na quarta seção).

Finalmente, cabe lembrar que uma das condicionalidades prevê a permanência na escola das crianças das famílias participantes do programa. Isso não seria uma forma de "ensinar a pescar"?

\section{Conditio sine qua non}

Essa última observação nos leva ao próximo ponto a ser considerado: as críticas às condicionalidades e ao caráter condicional do PBF.

No que diz respeito às primeiras, é necessário fazer uma distinção que nem sempre os críticos levam em conta: é preciso considerar se os problemas ligados à obrigatoriedade da presença escolar derivam da própria condicionalidade ou da maneira em que esse aspecto é gerido in loco pelos funcionários responsáveis, em primeiro lugar pelos gestores do PBF nas escolas. Existem vários estudos que relatam um nível elevado de stress, medo e ansiedade entre os participantes do programa devido ao temor de perder a bolsa, caso a criança seja obrigada a ficar longe da escola por um tempo superior ao consentido. $\mathrm{Na}$ realidade, este medo é injustificado de per si, uma vez que ausências 
justificadas (por exemplo, por doença) não deveriam resultar no corte da bolsa. Contudo, não é infrequente que até em situações deste tipo os gestores locais denunciem uma presumida inadimplência por parte da família e que isso resulte na suspensão dos pagamentos. Ora, nesses casos, o problema reside evidentemente na atitude dos gestores que, em vez de procurar informações ou de solicitar uma justificativa, preferem o caminho mais rápido e fácil (para eles), ou seja, relatar uma violação da condicionalidade. Mas nem sempre se trata de mero comodismo.

Recentes pesquisas empíricas efetuadas nas escolas, entrevistando gestores, diretores e simples professores, trouxeram à tona um nível elevado de preconceito contra os pobres em geral e os participantes do PBF em particular, inclusive contra as crianças. ${ }^{9}$ Espanta que justamente as pessoas que deveriam ter uma maior consciência da condição complicada dos estudantes pobres e, sobretudo, que têm o dever de ajudá-los a encontrar uma saída através da escola, manifestem tamanho cinismo, preconceito e, finalmente, indiferença humana em relação a crianças que, com certeza, não podem ser responsabilizadas pela sua situação. O que deveria ser objeto de estudo, portanto, é em que medida os problemas ligados às condicionalidades são causados por elas mesmas ou pela atitude dos agentes públicos que cuidam (ou deveriam cuidar) delas. ${ }^{10}$

Gostaria de responder neste contexto também às críticas avançadas por algumas teóricas feministas, mencionadas também por Melo, sobre o fato de o PBF não contribuir à emancipação das participantes do seu papel de mulher e mãe de família, fortalecendo antes os laços que as ligam a tal papel, ao atribuir-lhes a responsabilidade de gerir os

9. BRANDÃO, A; PEREIRA, R; DALT, S. Programa Bolsa Família: percepções no cotidiano da escola. Política e Trabalho, vol. 38, 2013, 215-232.

10. Isso não significa que o governo federal não tenha consciência da importância de uma correta interação com os gestores locais. Desde 2007 muitas coisas mudaram nesse sentido, como aponta Gala Díaz Langou (DÍAZ LANGOU, G. Validating one of the world's largest conditional cash transfer programmes. A case study on how an impact evaluation of Brazil's Bolsa Família Programme helped silence its critics and improve policy. Journal of Development Effectiveness, 2013, DOI: 10.1080/19439342.2013.861501). Também em relação aos gestores nas escolas, o MEC lançou recentemente um curso à distância que tem como público-alvo justamente os agentes públicos que lidam com crianças oriundas de famílias participantes do PBF. 
parcos recursos fornecidos pelo programa, de cuidar das condicionalidades, etc. Em si a crítica parece pertinente, mas somente se desconsiderarmos completamente a realidade das mulheres em questão. Com certeza, nenhuma das autoras que avançam esta crítica imagina seriamente que as participantes do programa teriam mais chances de alcançar um maior nível de emancipação se o programa fosse abolido, pois isso as recolocaria mais uma vez no status quo ante, substituindo de novo a preocupação com a presença escolar dos filhos pela preocupação ligada à tarefa de encontrar comida suficiente todos os dias, roupa, etc. A alternativa, portanto, seria um programa diferente, capaz de permitir ou até de fomentar tal emancipação. A maneira mais simples para tanto seria aumentar o valor da bolsa, a ponto de permitir às mulheres separar-se de maridos violentos e dominadores, ou abandonar a casa de pais autoritários, ou - quiçá - contratar babás e dedicar-se a uma carreira própria. Isso, contudo, parece-me irrealizável, pelo menos em curto e médio prazo. Até lá, a única maneira de ajudar as participantes a alcançar um maior grau de autonomia e de independência dos papeis tradicionais é o de oferecer-lhes apoio material através de políticas e estruturas públicas (CRAS, PBF, etc.), e muito foi e está sendo feito neste sentido. Mais uma vez, as críticas parecem desconhecer ou ignorar o fato de que o PBF é somente um entre muitos programas sociais e que já existem programas voltados especificamente a ajudar mulheres em situação de dificuldade familiar.

Cabe lembrar uma obviedade, a saber: os casos de opressão feminina e de violência doméstica não são limitados às camadas mais pobres da população, mas acontecem com triste frequência também nas classes média e alta. A diferença é que muitas vezes (mas nem sempre) as mulheres dessas classes têm a possibilidade material de separar-se, enquanto as mulheres pobres não conseguiriam manter a si mesmas e a seus filhos se resolvessem abandonar os maridos. Por isso é fundamental oferecer-lhes uma renda estável autônoma (neste sentido, o valor da bolsa é pequeno demais: seria muito melhor se elas tivessem uma renda fixa capaz de sustentar a si e aos filhos, inclusive na forma de uma renda básica universal com um valor suficientemente elevado). Poder-se-ia afirmar que a verdadeira emancipação se dará somente quando essas mulheres tiverem a capacidade de se manter pelo seu trabalho e de iniciar uma carreira autônoma. Ora, nessa visão de emancipação, que poderíamos chamar de neoliberal (o sujeito emancipado seria o sujeito economicamente autônomo e desvincula- 
do de qualquer compromisso - inclusive familiar) ${ }_{1}^{11}$ parece que as mulheres são colocadas perante uma alternativa: ou renunciar a ter filhos, ou, caso queiram tê-los, encontrar uma maneira de deixá-los com alguém que cuide deles. No primeiro caso, seria necessário considerar se de fato se trata de uma livre escolha ou de uma imposição ligada à situação do mercado de trabalho (neste caso, não haveria emancipação nenhuma). No segundo caso, haveria emancipação somente se as mulheres pudessem deixar os filhos em creches e escolas públicas. ${ }^{12}$ Em suma, a única solução viável para atingir uma verdadeira emancipação geral parece ser a instauração de um estado social de bem-estar fortemente ativo no setor de políticas destinadas às famílias. Mas no Brasil atual parece-me que infelizmente não há consenso político necessário para a criação de um estado deste tipo, que implicaria uma série de mudanças quase revolucionárias, começando pela renegociação da dívida pública, uma vez que o pagamento dos juros dela resultantes consome mais de $40 \%$ do orçamento federal.

Se o sentido da mencionada crítica feminista for, pelo contrário, o de acusar as participantes do programa de não ser suficientemente emancipadas por não querer sair de seu papel tradicional de esposa e mãe, isso seria ainda mais questionável. Como tentamos mostrar em nosso livro, o recebimento de uma renda regular através do PBF está abrindo pela primeira vez algumas fendas de autonomização para as mulheres em questão, possibilitando que passem a se considerar como indivíduos autônomos capazes de ter um mínimo de poder sobre sua vida. Em outras palavras, a capacidade de decidir-se em prol ou contra os papeis de mãe ou esposa pressupõe um nível de autonomia que essas mulheres em geral estão longe de ter atingido (pessoalmente duvido que até muitas mulheres de classe média ou alta sejam capazes disso, pois elas também são vítimas de uma sociedade machista e de um tipo de educação familiar que as educa a desejar servir seus homens,

11. Sobre o sujeito desvinculado como sujeito neoliberal, ver: BOLTANSKI, L; CHIAPELLO, E. O novo espírito do capitalismo. São Paulo: Martin Fontes, 2009, pp. 133-194.

12. Se tivessem que pagar por isso, a decisão de ter filhos se transformaria em um luxo acessível somente a quem tenha bons salários. E se contratassem babás, empregadas, etc., conseguiriam sua emancipação só ao preço da não emancipação de outras mulheres (as babás e as empregadas, justamente). 
como observava John Stuart Mill já em meados do século XIX).${ }^{13}$ Exigir que as participantes do PBF se emancipem já dos papeis tradicionais que lhes são atribuídos pelo seu ambiente social e familiar é, no mínimo, muito ingênuo.

Uma última anotação relativa à afirmação de que o PBF seria somente uma ampliação dos programas sociais iniciados pelo governo FHC. Considero tal afirmação bastante problemática. O programa Bolsa Escola introduzia a condicionalidade da presença escolar somente para um máximo de três crianças: se na família havia outras, era bem possível (e provável) que os pais as retirassem da escola para que pudessem trabalhar, deixando na escola as três crianças "necessárias" para manter a bolsa. O PBF estendeu a condicionalidade a todas as crianças da família, embora o valor variável fosse pago somente para um máximo de três crianças quando o programa foi criado em 2003 (hoje esse número subiu para cinco). Além disso, o PBF atinge também famílias sem crianças, pagando um valor básico (contrariamente ao Bolsa Escola ou ao Bolsa Alimentação, que só pagavam $\mathrm{R} \$ 15$ por criança até um máximo de três, como dito), e prevê uma série de valores variáveis para gestantes, bebês, etc. Em suma, não é a toa que traz o nome de Bolsa Família. As diferenças entre os dois programas vão além da mera questão do número de pessoas atingidas (cerca de 5 milhões de famílias no caso do Bolsa Escola e cerca de 1,5 milhão de famílias no caso do Bolsa Alimentação, por um lado, e 14 milhões de famílias no caso do $\mathrm{PBF})^{14}$, mas dizem respeito ao objetivo final e à maneira de alcançá-lo. Apesar do nome, a finalidade do Bolsa Escola não era, evidentemente, o fim do abandono escolar: obrigando os pais a escolher as três crianças que seguiriam na escola, o programa introduzia antes uma inaceitável e odiosa discriminação entre os membros de uma mesma família e, de fato, deixava na mesma situação inicial todas as crianças não atingidas por ele (lembro que as famílias participantes desse tipo de programa são tradicionalmente famílias numerosas, com elevado número de filhos).

13. MILL, J. On the subjection of women (1861). In: On Liberty and other essays. Oxford: Oxford University Press, 1991, pp. 469-582.

14. Se em vez das famílias, contássemos os indivíduos, as diferenças numéricas seriam ainda mais gritantes: de um máximo de 15 milhões de pessoas atingidas pelo Bolsa Escola passaríamos aos 55 milhões participantes do PBF. 


\section{O segundo governo Dilma entre imobilismo e apelo para a rua}

Duas leituras da política brasileira da última década me parecem merecer particular atenção, embora seja impossível fazer jus à sua complexidade no presente contexto (e por isso peço desculpas de antemão ao leitor e aos próprios autores, caso leiam estas linhas). Uma é a leitura de Marcos Nobre, centrada na noção de peemedebismo. A necessidade de procurar o apoio do PMDB para governar teria levado a um sistema de vetos cruzados, cujo resultado inevitável é um imobilismo, que sufoca qualquer tentativa séria de reforma e que teria levado a uma atrofia da confrontação política. À polarização PT-PSDB, que dominou as últimas quatro eleições presidenciais, não corresponde de fato à realização por parte dos dois partidos de políticas verdadeiramente alternativas, uma vez que o sistema de vetos cruzados torna impossível sair do status quo. ${ }^{15}$

A outra leitura, à qual pretendo recorrer, é a de André Singer, que identifica no lulismo uma forma política específica, fundada sobre maciças políticas sociais capazes de criar profundas transformações econômicas e sociais entre as camadas mais pobres da população, que tradicionalmente apoiaram os partidos mais conservadores, como o PFL/DEM no Nordeste e que agora passaram a formar uma base eleitoral para o PT. Enquanto isso, uma parcela relevante daquela classe média de escolaridade superior, que inicialmente apoiava o PT acabou afastando-se dele. Destarte, a polarização entre ricos e pobres substituiu-se àquela entre conservadores e progressistas. ${ }^{16} \mathrm{~A}$ última campanha eleitoral parece reforçar o diagnóstico de Singer relativamente à criação de uma contraposição de classe no Brasil, e no debate sobre as eleições acontecido no último encontro da Anpof, em Campos do Jordão, o próprio Marcos Nobre afirmou que, finalmente, veio à tona uma polarização política e social que poderia dar novo sentido à oposição entre PT e PSDB. ${ }^{17}$

15. NOBRE, M. Imobilismo em movimento. Da abertura democrática ao governo Dilma. São Paulo: Companhia das Letras, 2013.

16. SINGER, A. Os sentidos do lulismo. Reforma gradual e pacto conservador. São Paulo: Companhia das Letras, 2012.

17. Ver a matéria publicada na Folba: http://www1.folha.uol.com.br/ poder/2014/10/1540510-eleicoes-acirraram-a-luta-de-classes- 
Seria interessante tentar entender por que a classe média se tornou tão fortemente antipetista. Em parte isso se deu certamente por causa dos escândalos relativos a fenômenos de corrupção (do "mensalão" ao recente "escândalo da Petrobras"), que abalaram a diretoria do PT e que foram astutamente explorados por uma mídia parcial, que em muitos casos persegue uma agenda política específica e sempre fecha os olhos perante fenômenos análogos acontecidos no seio de partidos da oposição (em particular no caso do PSDB e dos vários escândalos como o "mensalão tucano", o "aécioporto", etc.). Em parte, porém, esse antipetismo surgiu por causa da percepção de que as políticas sociais ameaçam a situação de privilégio da própria classe média e de que o estilo de vida dessa última piorou em relação a épocas anteriores. Contratar uma empregada doméstica (algo considerado por séculos como uma obviedade nas famílias brasileiras de classe média alta) acarreta hoje custos maiores por causa da chamada "lei das domésticas"; o acesso a espaços como universidades, shoppings e aeroportos já não é exclusividade das parcelas mais abastadas da população; a introdução de cotas no acesso às universidades públicas e do ENEM em lugar do vestibular introduziu mudanças profundas num âmbito (os estudos superiores) que historicamente fora reservado quase exclusivamente aos jovens de classe média alta $_{i}$ o custo de vida tornou-se mais alto, por causa da inflação, contra a qual talvez o governo Dilma não fez tudo o que podia ser feito; foram introduzidos impostos sobre compras no exterior; até o aumento da venda de carros entre as classes populares foi visto como a causa pela qual os problemas de tráfego já existentes em muitas cidades se tornassem mais exasperados. Em suma, as mudanças econômicas provocadas pelas políticas sociais do governo do PT tiveram como consequência mudanças sociais bastante tangíveis no dia a dia, que provavelmente criaram na classe média tradicional a sensação de estar "caindo para trás" e de estar sendo alcançada pelas classes populares.

Na realidade, a desigualdade econômica entre classes permanece enorme, ${ }^{18}$ as rendas do capital financeiro e as taxas de lucro perma-

-no-pais-diz-filosofo.shtml. Ver também: NOBRE, M. A polarização voltou. Piauí, no 98, 2014.

18. Cabe lembrar as palavras de três economistas brasileiros: "A desigualdade no Brasil é muito alta e estável. O $1 \%$ mais rico da população adulta concentra mais de um quarto de toda a renda do país. O $5 \%$ mais ricos detém quase 
necem elevadas, e até os gastos no exterior alcançaram novos recordes em 2013, assim que a percepção de que as coisas "estão feias", de que a situação econômica do país estaria terrível e de que estamos à beira de um abismo no qual o Brasil cairá inevitavelmente por culpa do governo petista - como afirma uma queixa que se houve muito frequentemente entre membros da classe média e que aparece continuamente na mídia - não parece ter um fundamento real e dá antes a impressão de ser o resultado de medos injustificados ligados à mencionada perda de status percebida (erroneamente) pela classe média tradicional como perda de poder econômico e aquisitivo. Isso pode explicar a reação quase histérica de parte do eleitorado conservador à derrota de outubro.

Seja como for, não foi somente o país que saiu dividido das eleições de 2014, mas também o parlamento - e isso me parece ainda mais grave. O sistema de vetos cruzados mencionados por Nobre saiu reforçado das eleições, com uma fragmentação partidária sem precedentes (de 22 passamos a 28 legendas partidárias presentes na Câmara dos Deputados, enquanto no Senado o número de partidos aumentou de 16 para 18). O PMDB, o grande vilão da tese do peemedebismo, saiu enfraquecido (perdeu 13 cadeiras) e dividido (33 deputados, a metade exata dos 66 deputados eleitos, declararam na eleição seu apoio para o Aécio Neves) ${ }_{1}^{19}$ e pode ser que tente recuperar forças nos próximos quatro anos destacando-se como partido mais ativo e "ideológico", na esteira do PT e do PSDB - e a maneira mais simples para isso seria a de votar contra o governo e apoiar a oposição em questões marcantes capazes de polarizar o eleitorado. Além disso, o Congresso que saiu das eleições de 2014 é em sua maioria fortemente conservador ou abertamente reacionário. ${ }^{20} \mathrm{~A}$ presidenta Dilma enfrentará grandes dificuldades em encontrar maiorias para projetos de lei que visem

metade da renda. A concentração é tamanha que um milésimo das pessoas acumula mais renda que toda a metade mais pobre da população junta" (MEDEIROS, M.; SOUZA, P.; CASTRO, F. O Topo da Distribuição de Renda no Brasil: primeiras estimativas com dados tributários e comparação com pesquisas domiciliares, 2006- 2012. Publicado em 14/08/2014. Acessível em: SSRN: http://ssrn.com/ abstract $=2479685$ )

19. http://eleicoes.uol.com.br/2014/noticias/2014/10/14/bancada-do-pmdb-pro-aecio-critica-propaganda-de-dilma.htm

20. http://brasil.elpais.com/brasil/2014/10/08/politica/1412729853_844912.html 
mudar substancialmente a situação social e econômica do país (só para dar um exemplo, "a Frente Parlamentar da Agropecuária, que busca um recrudescimento dos direitos indígenas previstos na Constituição também aumentará de 191 a 257 representantes", ${ }^{21}$ ou seja, a metade mais um dos 513 deputados da Câmara). O mesmo eleitorado que, no Norte e Nordeste, votou maciçamente na presidenta Dilma, elegeu deputados e senadores de outras legendas que não o PT. Com um Congresso tão fragmentado e conservador, é difícil imaginar que o governo tenha força para realizar as grandes reformas políticas e sociais que o Brasil precisa. A presidenta poderia apelar para o povo, buscando o apoio de alguns dos movimentos populares que foram para a rua em 2013, mas parece-me improvável que o PT recorra a esta estratégia, pelo menos de maneira sistemática, uma vez que a situação não parece muito propícia para tais práticas de participação popular (veja-se a reação negativa da mídia ao decreto presidencial 8.243 que estabelecia a consulta a conselhos populares antes da implementação de políticas públicas e, sobretudo, a anulação do decreto por parte da Câmara dos deputados no dia 28 de outubro, dois dias depois da reeleição da presidenta). ${ }^{22} \mathrm{O}$ segundo governo Dilma corre o risco de ficar preso entre imobilismo e o apelo para a rua e, provavelmente, assistiremos a um aumento do uso das medidas provisórias, que tinha diminuído no primeiro mandato.

Portanto, se, por um lado, é certamente legítimo perguntar-se o que o segundo governo Dilma deveria fazer em termos de políticas sociais, de medidas econômicas, de direitos civis, etc. (aliás, é tarefa de cada cidadão apontar para possíveis finalidades a serem realizadas pelo governo federal ou pelos governos locais), por outro, não se pode fingir, ao avançar estas exigências legítimas, que não existem obstáculos (em alguns casos insuperáveis) à realização dos fins em questão. Mais uma vez a política se demonstra a arte do possível - o que, porém, acaba gerando profunda insatisfação nos cidadãos e alienando boa parte do eleitorado, quer em relação aos partidos políticos, quer em relação à própria democracia representativa.

21. Ibidem.

22. http://www.planalto.gov.br/ccivil_03/_Ato2011-2014/2014/Decreto/D8243. htm ; http://g1.globo.com/politica/noticia/2014/10/camara-derruba-decreto-sobre-conselhos-populares.html 
Para as camadas mais pobres da população, que dependem das políticas sociais federais, a situação política oriunda das eleições de 2014 pode significar uma estagnação se o governo não encontrar uma maneira de tomar e implementar medidas ainda mais incisivas e estruturais do que as atuais. Se, contudo, isso não acontecer, seria apressado culpar o governo Dilma e o PT ou denunciar a timidez de programas como o PBF, pois um diagnóstico desse tipo negligenciaria as condições políticas reais nas quais a presidenta é obrigada a movimentar-se atualmente. Nesse sentido, avanços e mudanças dependem não somente da ação do governo, mas também da capacidade de pressão das organizações sociais interessadas na transformação política, econômica e social do Brasil. ${ }^{23}$

\section{Referências}

BOLTANSKI, L.; CHIAPELLO, E. O novo espírito do capitalismo. São Paulo: Martin Fontes, 2009.

BRANDÃO, A.; PEREIRA, R.; DALT, S. Programa Bolsa Família: percepções no cotidiano da escola. Política e Trabalho, vol. 38, 2013, pp. 215-232.

CAMPELlO, T.; NERI, M. (orgs.). Programa Bolsa Familia. Uma década de inclusão e cidadania. Brasília: IPEA, 2013.

DÍAZ LANGOU, G. Validating one of the world's largest conditional cash transfer programmes. A case study on how an impact evaluation of Brazil's Bolsa Família Programme helped silence its critics and improve policy. Journal of Development Effectiveness, 2013, DOI: 10.1080/19439342.2013.861501.

FONSECA, P.; CUNHA, A.; BICHARA, J. O Brasil na Era Lula: Retorno ao desenvolvimentismo? Nova Economia, vol. 23, n 2, 2013, pp. 403-428.

KERSTENETZKY, C. Políticas sociais: focalização ou universalização? Revista de Economia Política, vol. 26. No 4 (104), 2006, pp. 564-574.

MEDEIROS, M.; SOUZA, P.; CASTRO, F. O Topo da Distribuição de Renda no Brasil: primeiras estimativas com dados tributários e comparação com pesquisas domiciliares, 2006- 2012. Publicado em 14/08/2014. Acessível em: SSRN: http://ssrn.com/abstract $=2479685$.

23. Agradeço Amaro Fleck e Gisa Aver pelas considerações e pelos comentários ao presente texto. 
MELO, R. Resenha de Vozes do Bolsa Família: Autonomia, dinheiro e cidadania, de Walquiria Leão Rego e Alessandro Pinzani (São Paulo: Editora Unesp, 2013). Cadernos de Filosofia Alemã, vol. 19, n 1, 2014, pp. 213-221.

MILL, J. On Liberty and other essays. Oxford: Oxford University Press, 1991.

MOLLO, M.; FONSECA, P. Desenvolvimentismo e novo-desenvolvimentismo: raízes teóricas e precisões conceituais. Brazilian Journal of Political Economy, vol. 33, n 2, 2013, pp. 222-239.

NOBRE, M. Imobilismo em movimento. Da abertura democrática ao governo Dilma. São Paulo: Companhia das Letras, 2013.

A polarização voltou. Piauí, no 98, 2014.

SINGER, A. Os sentidos do lulismo. Reforma gradual e pacto conservador. São Paulo: Companhia das Letras, 2012. 